\title{
The effect of chemical modification of wood in ionic liquids on the supermolecular structure and mechanical properties of wood/polypropylene composites
}

\author{
Slawomir Borysiak · Aleksandra Grząbka-Zasadzińska • Majka Odalanowska • \\ Andrzej Skrzypczak • Izabela Ratajczak
}

Received: 21 December 2017/Accepted: 5 June 2018/Published online: 13 June 2018

(C) The Author(s) 2018

\begin{abstract}
Effects of chemical modification of wood with innovative ionic liquid on the supermolecular and morphology of wood/polypropylene composites were investigated using X-ray diffraction, hot stage optical microscopy, and differential scanning calorimetry. For the first time the chemical treatment of wood was conducted solely with newly synthesized ionic liquid, didecyldimethylammonium bis(trifluoromethylsulfonyl)imide. The modification was found to be responsible for significant changes in nucleating abilities of wood in polypropylene matrix. These findings were confirmed by crystallization temperature, crystal conversion, crystallization half-time parameters, as well as observation of transcrystalline structures. Ionic liquid treatment of wood influenced also formation of polymorphic forms of polymer matrix. In contrast to composites with untreated wood, in composites with modified wood filler formation of $\beta$-phase of polypropylene was observed. This fact was discussed in view of differences in nucleating activity of lignocellulosic filler, resulting from chemical
\end{abstract}

S. Borysiak $(\bowtie) \cdot$ A. Grząbka-Zasadzińska ·

M. Odalanowska · A. Skrzypczak

Institute of Chemical Technology and Engineering,

Poznan University of Technology, Berdychowo 4,

60965 Poznan, Poland

e-mail: Slawomir.Borysiak@put.poznan.pl

I. Ratajczak

Department of Chemistry, Poznań University of Life

Sciences, Wojska Polskiego 75, 60625 Poznan, Poland treatment with ionic liquid. Moreover, a relationship between mechanical properties of composites and the phenomena taking place at the polymer-filler interface, controlled by chemical modifications of lignocellulosic components, was evaluated.

Keywords Polypropylene/wood composites · Chemical treatment $\cdot$ Ionic liquids $\cdot$ Mechanical properties $\cdot$ Supermolecular structure

\section{Introduction}

In recent years, a growing interest in thermoplastic composites reinforced with a natural component, such as wood, sisal, jute, hemp, and flax fibre can be noticed. The lignocellulosic materials are biodegradable and their annual biosphere production was estimated to be $90 \times 10^{9}$ metric tons. Thus, they represent the most obvious, renewable resource for production of biocomposites (Feifel et al. 2015; Kalia et al. 2011; Michalska-Pożoga et al. 2016). Moreover, lignocellulosic fibres, due to the strong cellulose backbone structure and high strength/weight ratio, are at an advantage when compared with many conventional reinforcing materials. What is also crucial, they cause less abrasion to the processing machines as do glass fibres, which also give a large amount of ash on combustion (Joseph et al. 1999). 
The key problem in producing composite materials is to achieve good interphase adhesion between the polymer matrix and the lignocellulosic filler (Thakur et al. 2013). Moreover, the unmodified lignocellulosic components show a tendency towards aggregation, which is a consequence of the intermolecular interactions (H-bonds) between the molecules of the filler. This tendency is reflected by poor dispersion of the filler in the polymer matrix and deterioration of the mechanical properties of the product (Khoshkava and Kamal 2014; Oksman and Clemons 1998; Zhang et al. 2009 b). For this reason many researchers have been searching for methods of chemical or physical modifications of the components. Literature (Burley et al. 2004; Hill 2007; Thakur et al. 2014a) provides numerous methods of chemical modification of lignocellulosic constituents that have been developed. The following derivatives are known: acetates, carboxymethylates, benzoylates, urethanes, (meth)acrylates, carbonates, sulfates, sulfonates, phthalates, tritylates, furorates, maleated esters, isocyanates or ester resins (Bagheri et al. 2008; Edgar et al. 2001; Klemm et al. 2005; Köhler and Heinze 2007; Thakur et al. 2014b; Wu et al. 2004). These modification methods enable improvement of mechanical properties and dimensional stability of the composites (Dominkovics et al. 2007; Faruk et al. 2012; Harper 2009; Zafeiropoulos et al. 2001).

Although there have been quite a number of studies on the chemical modification of lignocellulosic materials, so far, little attention has been paid to the use of ionic liquids for treatment of these fillers. Ionic liquids (IL) are organic salts consisting of organic cation and organic or nonorganic anion with melting temperature below $100{ }^{\circ} \mathrm{C}$ (Wasserscheid and Welton 2008). They are characterized with an ability to dissolve organic and nonorganic matter and therefore they are being called solvents of new generation, "green solvents" (Brandt et al. 2013). Currently, chemical modification of lignocellulosic fillers is most commonly realized with use of concentrated, toxic reagents. There is also a necessity to separate particles of the filler from such solutions. Therefore, the great advantage of using ionic liquid in modification process is the fact that this reagent can be easily recovered, purified, and used multiple times. However, it is important to bear in mind that recycling of ionic liquid regards only defined, individual process (e.g. extraction of specific impurities and, or, unreacted substrates with traditional solvents).

Moreover, IL have many attractive properties, including chemical and thermal stability, non-flammability, and immeasurably low vapor pressure (Zhu et al. 2006). Nevertheless, the ionic liquids were firstly synthesized as reagents enabling dissolution of cellulose. They have also been used as solvent for a wide range of modifications of cellulose. Acrylate, benzoylate, carbamate, and choline acetate derivatives of the biopolymer were successfully prepared in many ionic liquids (Bagheri et al. 2008; Liu et al. 2007; Ninomiya et al. 2017; Schenzel et al. 2014; Wu et al. 2004; Xie et al. 2007; Zhang et al. 2009c). It should be stressed that up to now no method of hydrophobization of lignocellulosic fillers with ionic liquids has been developed. Application of newly synthesized ionic liquid enables chemical modification of wood without need to use any other, classical wood modifiers.

It is a well-known fact that the natural fillers can cause changes in morphology and crystallinity of the interphase regions. Some fillers can initiate heterogenic nucleation and significantly influence the course of crystallisation of polymers. Modification of the filler changes its nucleation abilities, leading to alterations in the interactions between the filler and the polymer matrix. However, the character of the change can be also different. According to some authors (Joseph et al. 2003; Lee et al. 2010; Lenes and Gregersen 2006; Son et al. 2000; Zafeiropoulos et al. 2001), chemical modification of the filler leads to a decrease in its nucleation abilities, while according to others (Joseph et al. 2003; Zafeiropoulos et al. 2001), it increases nucleation ability of the filler. A detailed analysis of literature data regarding the influence of the chemical modifications of lignocellulose fillers on supermolecular structure of polypropylene is given in (Borysiak 2013a). Finding a relationship between development of the nucleation ability of lignocellulosic filers and the mechanical properties of the composites is especially important from the application point of view. It is known that the interphase surface transfers the stress appearing in the system. Weak interphase interactions are responsible for appearance of cracks and delamination of the composites, leading to considerable deterioration of the mechanical strength.

Another issue is the influence of polymorphism of the polypropylene matrix (Keith 1959). Interesting 
question that needs to be considered is the effect of changes in the interphase adhesion induced by the filler modification on formation of polymorphic structures in PP matrix in the composite systems.

This work is a part of the comprehensive investigation of the influence of chemical modification of wood on the interfacial phenomena, as well as on the properties of lignocellulosic-polypropylene composite materials. The aim of this study was to evaluate the effect of innovative chemical surface treatments of wood with ionic liquid on the supermolecular structure of polypropylene matrix. Moreover, it is expected that the results will enable better understanding of the relationship between the mechanical properties and the nucleation ability of the treated and untreated wood. In order to resolve this issue, the effect of the wood treatment on the properties of the composites must be clearly defined.

\section{Experimental}

\section{Materials}

Isotactic polypropylene (PP), Moplen HP500 N $\left(\mathrm{MFI}_{230}{ }^{\circ} \mathrm{C} / 2.16 \mathrm{~kg}-2.4-3.2 \mathrm{~g} / 10 \mathrm{~min}\right.$, isotacticity$95 \%, \mathrm{~T}_{\mathrm{m}}=163-164{ }^{\circ} \mathrm{C}$ ) produced by Basell Orlen Polyolefins (Plock, Poland) was used as a matrix. The pine wood (Pinus sylvestris L.), supplied by Forestry-Kaminska (Poland). Wood samples were cut and screened by the FRITSCH Cutting Mill Pulverisette 19 with rotor speed of $2.800 \mathrm{rpm}$. Particle characteristics were determined by analysis of SEM micrographs. The average particle size was $0.5-1.0 \mathrm{~mm}$ and aspect ratio of the particles (L/D) was in range 5-6. Some irregular particles were also observed but they were not used for determining the particle size distribution.

The wood filler was dried at $70{ }^{\circ} \mathrm{C}$ in an aircirculating oven for $24 \mathrm{~h}$ prior to use. The moisture content of the pine wood was less than $1 \mathrm{wt} \%$. The unmodified wood was subjected to the process of chemical modification.

Synthesis of innovative ionic liquid

In this work, the innovative method of modification was used. Ionic liquid was prepared by the ion exchange reaction. To aqueous solution of didecyldimethylammonium chloride aqueous, solution of $\mathrm{LiN}\left(\mathrm{SO}_{2} \mathrm{CF}_{3}\right)_{2}$ was added (1:1.1) and mixture was stirred at room temperature for $2 \mathrm{~h}$. The aqueous phase was decanted and the product was washed with distilled water until chloride ions were no longer detected using $\mathrm{AgNO}_{3}$. Final product, didecyldimethylammonium bis(trifluoromethylsulfonyl)imide, was used for the modification of wood. Scheme of the synthesis is shown in reaction 1 .

\section{Characterization of ionic liquid}

Newly synthesized ionic liquid (Fig. 1) was subjected to nuclear magnetic resonance and rheology tests.

The ${ }^{1} \mathrm{H}$ nuclear magnetic resonance (NMR) and ${ }^{13} \mathrm{C}$ NMR spectra were recorded on a Brucker spectrometer at $600 \mathrm{MHz}$ with tetramethylsilane as standard for ${ }^{1} \mathrm{H}$ NMR and $150 \mathrm{MHz}$ for ${ }^{13} \mathrm{C}$ NMR. The results of NMR measurements are as follows:

${ }^{1} \mathrm{H}$ NMR $\left(600 \mathrm{MHz}\right.$, temp. $298 \mathrm{~K}$, DMSO- $d_{6}$, TMS): $\delta[\mathrm{ppm}]=0.85-0.88(\mathrm{t}, J=6.9 \mathrm{MHz}, 6 \mathrm{H})$; $1.26-1.32(\mathrm{~m}, 28 \mathrm{H}) ; 1.63-1.65(\mathrm{q}, J=3.9 \mathrm{MHz}, 4 \mathrm{H})$; $2.98(\mathrm{~s}, 6 \mathrm{H}) ; 3.20-3.23(\mathrm{~m}, 4 \mathrm{H})$;

${ }^{13} \mathrm{C}$ NMR (150 MHz, temp. $298 \mathrm{~K}$, DMSO- $d_{6}$, TMS): $\delta[\mathrm{ppm}]=13.77 ; 21.60 ; 22.03 ; 25.68 ; 28.38$; $28.61 ; 28.73 ; 28.83 ; 31.23 ; 49.91 ; 62.89 ; 116.26$; $118.40 ; 120.53 ; 122.66$.

Shear rheology data of didecyldimethylammonium bis(trifluoromethylsulfonyl)imide was collected on an Haake RheoStress 150 rheometer, with a cone and plate geometry and controlled rate mode. The samples were subjected to a steady shear test over a velocity shear rate range of $1-200 \mathrm{~s}^{-1}$, at different temperatures (range $10-60{ }^{\circ} \mathrm{C}$ ). The measurements were made in both heating and cooling modes. Viscosity of IL as a function of temperature at shear rate of $100 \mathrm{~s}^{-1}$ (for heating and cooling mode) is shown in Fig. 2.

Chemical modification of wood with ionic liquid

The dry wood flour was treated at room temperature in ethanol solution of didecyldimethylammonium bis(trifluoromethylsulfonyl)imide (1:0.2) for $3 \mathrm{~h}$. Vigorous stirring of the slurry was achieved using mechanical stirrer at a rate of $100 \mathrm{rpm}$. When the time of the reaction expired, the slurry was filtered and the modified wood was extracted with ethanol in the Soxhlet apparatus for $4 \mathrm{~h}$, to eliminate the unreacted ionic liquid. Finally, the wood was dried in the air at an 


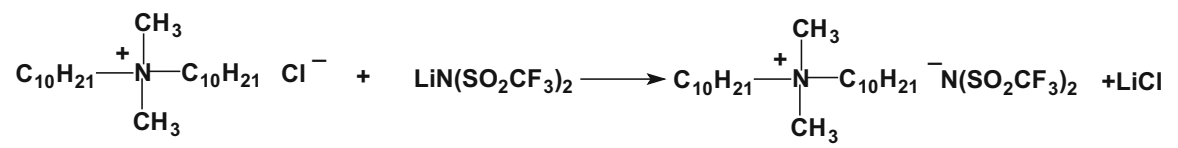

Reaction 1 Scheme of didecyldimethylammonium bis(trifluoromethylsulfonyl)imide synthesis

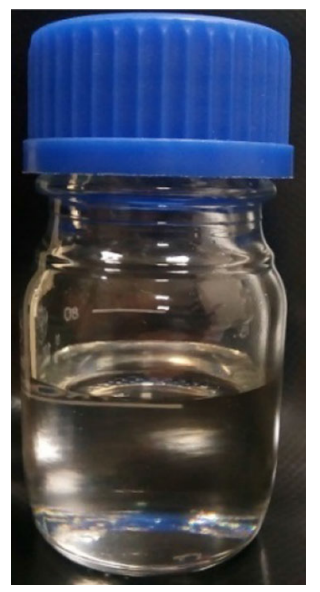

Fig. 1 Optical image showing synthesized didecyldimethylammonium bis(trifluoromethylsulfonyl)imide

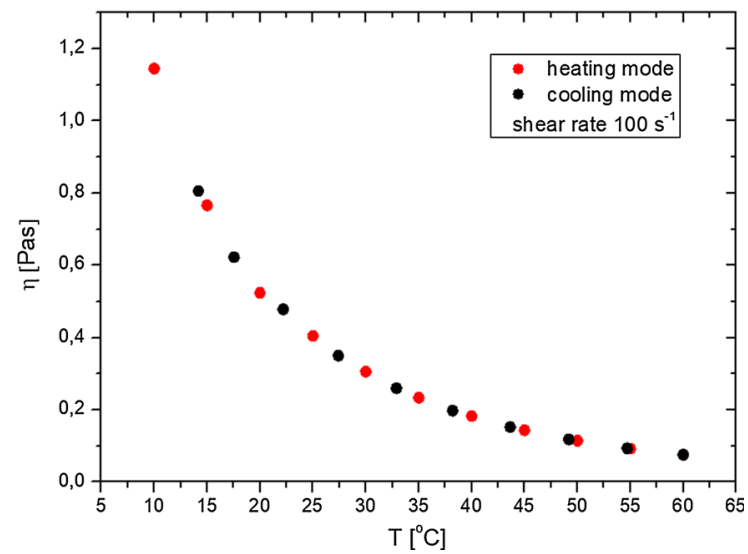

Fig. 2 Viscosity of IL as a function of temperature at shear rate of $100 \mathrm{~s}^{-1}$ (for heating and cooling mode)

elevated temperature (ca. $110{ }^{\circ} \mathrm{C}$ ) until a constant weight. The effectiveness of the modification process of wood was confirmed by the FTIR spectra. For this purpose wood samples were mixed with $\mathrm{KBr}$ (SigmaAldrich, Germany) at a 1/200 mg ratio. Spectra were registered using an Infinity spectrophotometer by Mattson with Fourier transform at a range of $500-4000 \mathrm{~cm}^{-1}$ at a resolution of $2 \mathrm{~cm}^{-1}$, registering 64 scans.
Moreover, Weight Percent Gain (WPG) values were obtained in order to quantitatively follow the modification efficiency of the wood.

Preparation of composite materials

The composites of PP and wood (40 wt $\%$ ) were produced in a two-stage process. In the first stage, feeding of pellets was performed using extruder with a length-to-diameter ratio $\mathrm{L} / \mathrm{D}=25$. The temperature of the processing zones I (solid conveying zone), II (melting zone), III (pumping zone), and the die were 140, 180, 195 and $195{ }^{\circ} \mathrm{C}$, respectively. The extruder screw speed was $40 \mathrm{rpm}$. The cooled strands were subsequently pelletized into granules and dried in an oven for $2 \mathrm{~h}$ at $105{ }^{\circ} \mathrm{C}$. In the second stage, composite test specimens were injection moulded at $200{ }^{\circ} \mathrm{C}$. The mould temperatures of $30{ }^{\circ} \mathrm{C}$, injection speed of $110 \mathrm{~mm} / \mathrm{s}$, and cooling time of samples in injection mould of $30 \mathrm{~s}$ were applied. Specimens were prepared according to ISO standard procedure for tensile and impact testing.

X-ray diffraction

The supermolecular structures of composites filled with untreated and treated wood were analysed by means of wide angle X-ray scattering (WAXS) using $\mathrm{Cu} \mathrm{K} \alpha$ radiation at $30 \mathrm{kV}$ and $25 \mathrm{~mA}$ anode excitation. The $\mathrm{X}$-ray diffraction patterns were recorded for the angles in range of $2 \Theta=10-30^{\circ}$ with step of $0.04^{\circ} / 3 \mathrm{~s}$. Deconvolution of peaks was performed by the method proposed by Hindeleh and Johnson (Hindeleh and Johnson 1971), improved and programmed by Rabiej (Rabiej 1991). After separation of X-ray diffraction lines, the crystallinity index $\left(\mathrm{X}_{\mathrm{c}}\right)$ of wood after chemical treatment was calculated by comparison of areas under crystalline peaks and amorphous curve. Moreover, the changes in the supermolecular structure of composite materials were investigated. The relative fraction of the $\beta$-phase of PP (k) was determined by the Turner-Jones equation 
(Jones et al. 1964) and analysed as a function of wood treatments.

Hot stage optical microscopy

Polarized optical microscope Labophot-2 (Nikon) equipped with Linkam TP93 hot stage was used for observation of PP crystallization in the presence of filler. It was connected to Panasonic CCD camera and to a computer. Small pieces of composites film placed on a microscope slide were heated to $200{ }^{\circ} \mathrm{C}$ and kept in that temperature for $5 \mathrm{~min}$ in order to eliminate their thermal history. The samples were then rapidly cooled to $134{ }^{\circ} \mathrm{C}$, since in this temperature the crystallisation process took place.

The growth of the transcrystalline layer was determined based on observations of PP crystallisation in the presence of pure and modified wood. Nucleation ability of fillers in PP matrix was determined by relationship between transcrystalline thickness and crystallization time. The slope of the straight line represents the crystal growth rate.

\section{Differential scanning calorimetry}

The experiments of differential scanning calorimetry were performed with Netzsch DSC 200 calorimeter under dynamic conditions. In stage I samples were heated from room temperature to $200{ }^{\circ} \mathrm{C}$ at a rate of $10{ }^{\circ} \mathrm{C} / \mathrm{min}$ under a nitrogen atmosphere and held for 5 min to destroy any residual nuclei. In stage II samples were cooled to room temperature at a cooling rate of $5{ }^{\circ} \mathrm{C} / \mathrm{min}$. This procedure was repeated two times and data recorded during the second segment were used for calculations. The kinetic parameters of crystallization of PP in pure wood and treated wood like the crystal conversion $(\alpha)$ and the half-time of crystallization $\left(\mathrm{t}_{0.5}\right)$ were determined. The crystallization temperature $\left(\mathrm{T}_{\mathrm{c}}\right)$ of the composite materials were determined as the highest temperature of the exothermic peaks. The enthalpy of the endothermic transition was defined as the area below the curve of the transformation. Based on the calculated values for the enthalpy of crystallisation $(\mathrm{H})$, the extent of crystallisation (crystal conversion), $\alpha$ was calculated in accordance to Eq. 1:

$\alpha=\int_{T_{0}}^{T}\left(\frac{d H}{d T}\right) d T / \int_{T_{0}}^{T \propto}\left(\frac{d H}{d T}\right) d T$ where $T_{o}$ is the onset temperature, $T$ is the temperature at time $t, T_{\infty}$ is the temperature when crystallization completes, $d H$ is the enthalpy of crystallization.

The half-time of crystallization was obtained from a plot of crystal conversion $(\alpha)$ against time ( $t$ ). At least three specimens of each composite were tested, standard deviations were determined as well.

Mechanical testing of composites

The tensile properties were measured according to ISO 527 standard. Tensile tests were carried out using a Zwick (model Z020) universal mechanical testing machine with a load cell capacity of $20 \mathrm{kN}$ at a crosshead speed of $1 \mathrm{~mm} / \mathrm{min}$ for modulus determination and of $50 \mathrm{~mm} / \mathrm{min}$ for tensile strength and elongation at break measurements. The tensile strength and modulus were determined from the stress-strain curves. Charpy impact strength tests were conducted on notched samples according to ISO 179 standard with a Zwick 5102 impact test device. At least ten replicates were tested for each property under each formulation.

\section{Results and discussion}

Analysis of chemical modification of wood filler with ionic liquid

Figure 3 shows FTIR spectra of pine wood after the reaction with didecyldimethylammonium bis(trifluoromethyl sulfonyl)imide in different wavenumber (a $\left(4000-500 \mathrm{~cm}^{-1}\right)$ and $\mathrm{b}\left(1600-1000 \mathrm{~cm}^{-1}\right)$. The presented spectra showed changes in the structure of wood filler treated with the ionic liquid (spectra B) in comparison to untreated wood (spectra A). Spectra of wood after the reaction with ionic liquid contain a band at $1350 \mathrm{~cm}^{-1}$ characteristic of the $\mathrm{S}=\mathrm{O}$ and $\mathrm{O}-\mathrm{N}$ bonds, a band at $1195 \mathrm{~cm}^{-1}$ characteristic of $\mathrm{S}=\mathrm{O}$, a band at $1140 \mathrm{~cm}^{-1}$, which indicate the presence of stretching vibrations of the $\mathrm{CF}_{3}$ bonds as well as a band at $1060 \mathrm{~cm}^{-1}$ characteristic of the $\mathrm{C}-\mathrm{N}$ bond. It is worth emphasizing that not only the presence of these bands in spectra of wood after the reaction with ionic liquid and after leaching with water but also chemical interactions between hydroxyl groups from wood and the ammonium group from 

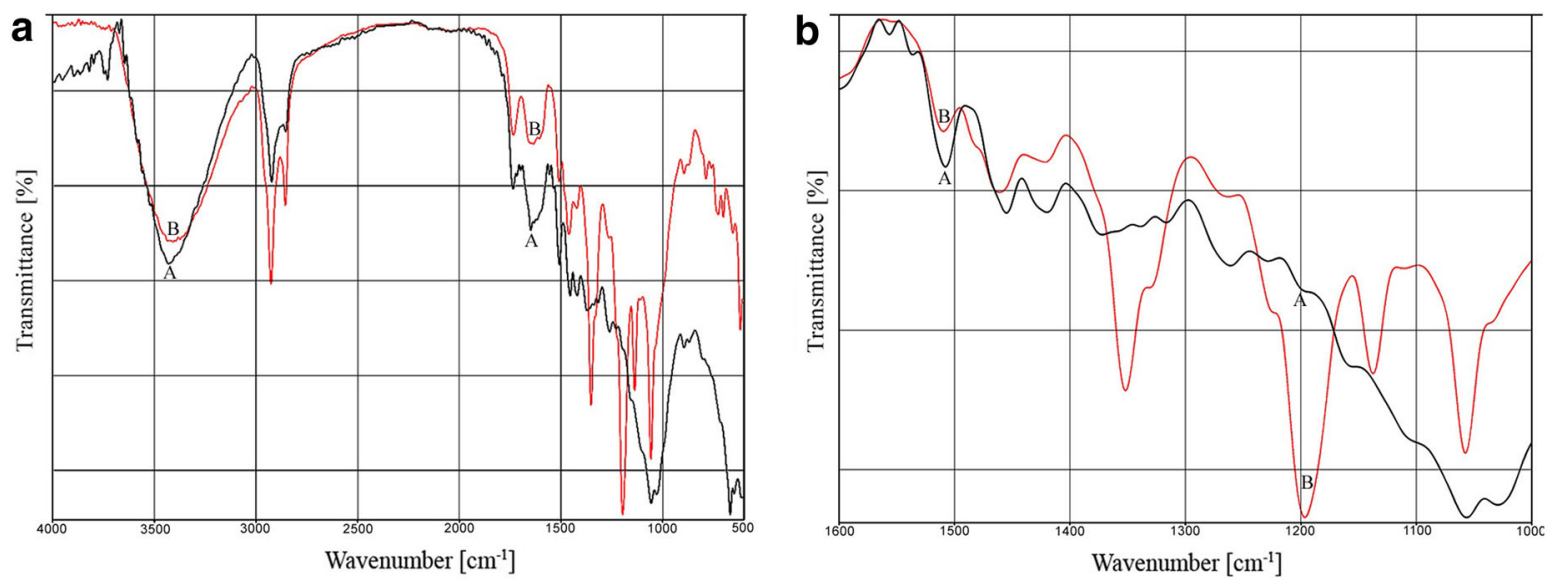

Fig. 3 FTIR spectra of untreated wood (A) and wood treated with ionic liquid (B) a $\left(4000-500 \mathrm{~cm}^{-1}\right)$ and b $\left(1600-1000 \mathrm{~cm}^{-1}\right)$

the ionic liquid were confirmed in a study by Woźniak et al. (2017). In this work chemical interaction between wood and didecyldimethylammonium bis(trifluoromethylsulfonyl)imide was confirmed by elemental analysis. Additionally, our data indicate modification of wood with ionic liquid cause increase in the WPG (ca. 7\%). These results were also confirmed in a study by Lee et al. (2014).

FTIR and elemental analysis indicate chemical interaction between wood and ionic liquid. The proposed interaction between hydroxyl groups of wood and the ammonium groups from the ionic liquid occurring during the modification process is illustrated in Fig. 4.

The WAXS tests conducted on wood fillers show changes in their supermolecular structures. In Fig. 5 characteristic diffraction peaks at $2 \Theta \mathrm{ca} .15^{\circ}, 17^{\circ}$, and $22^{\circ}$ coming from polymorphic form of cellulose I were observed.

It can be seen that intensities of these peaks originating from untreated wood are higher than for treated wood. Calculations have shown that ionic liquid treatment was responsible for lowering degree of crystallinity of wood down to $48 \%$ (for unmodified wood $\mathrm{X}_{\mathrm{c}}=64 \%$ ). The observed decrease of crystallinity degree can be ascribed to limitation of interand intra-molecular hydrogen bonds within the cellulose crystalline region. It results from the reaction of the ionic liquid with the hydroxyl groups of the cellulose, which in consequence led to a decrease in the crystallinity. Decrease of crystallinity degree, caused by change in mobility of cellulose chains, was also observed for other cellulosic fillers and modifiers, e.g. 1-allyl-3-methylimidazolium chloride and dimethylsulfoxide (Xu et al. 2008). Moreover, the results of X-ray photoelectron spectroscopy (XPS) confirm changes in the H-bond network of cellulose after ionic liquids treatment, too (Zhang et al. 2009a).

Effect of treatment on the nucleation ability of wood in polypropylene matrix

Research on defining the nucleating abilities of the filler surface is crucial since fillers can play an important role in process of polymer matrix crystallization and in consequence, define the mechanical properties of composites. An additional factor requiring consideration is the fact that the surface of the wood filler can be also modified. It should be emphasized that until now ionic liquid treatment was not applied in order to enhance the adhesion in wood composite materials.

Differential scanning calorimetry tests were carried out to examine the influence of the chemical treatment of wood on its nucleating abilities. In Fig. 6 typical exothermic behavior of PP and PP/wood composites are presented.

Peaks in thermograms show the crystallization process of PP. Addition of wood filler to polymer matrix caused the peaks to shift towards higher temperatures. A relationship between the crystallization temperature and filler type can be observed. Incorporation of unmodified wood into PP matrix resulted in significant increase of $\mathrm{T}_{\mathrm{c}}$ (by $9{ }^{\circ} \mathrm{C}$ ). On the other hand, ionic liquid treatment induced less 

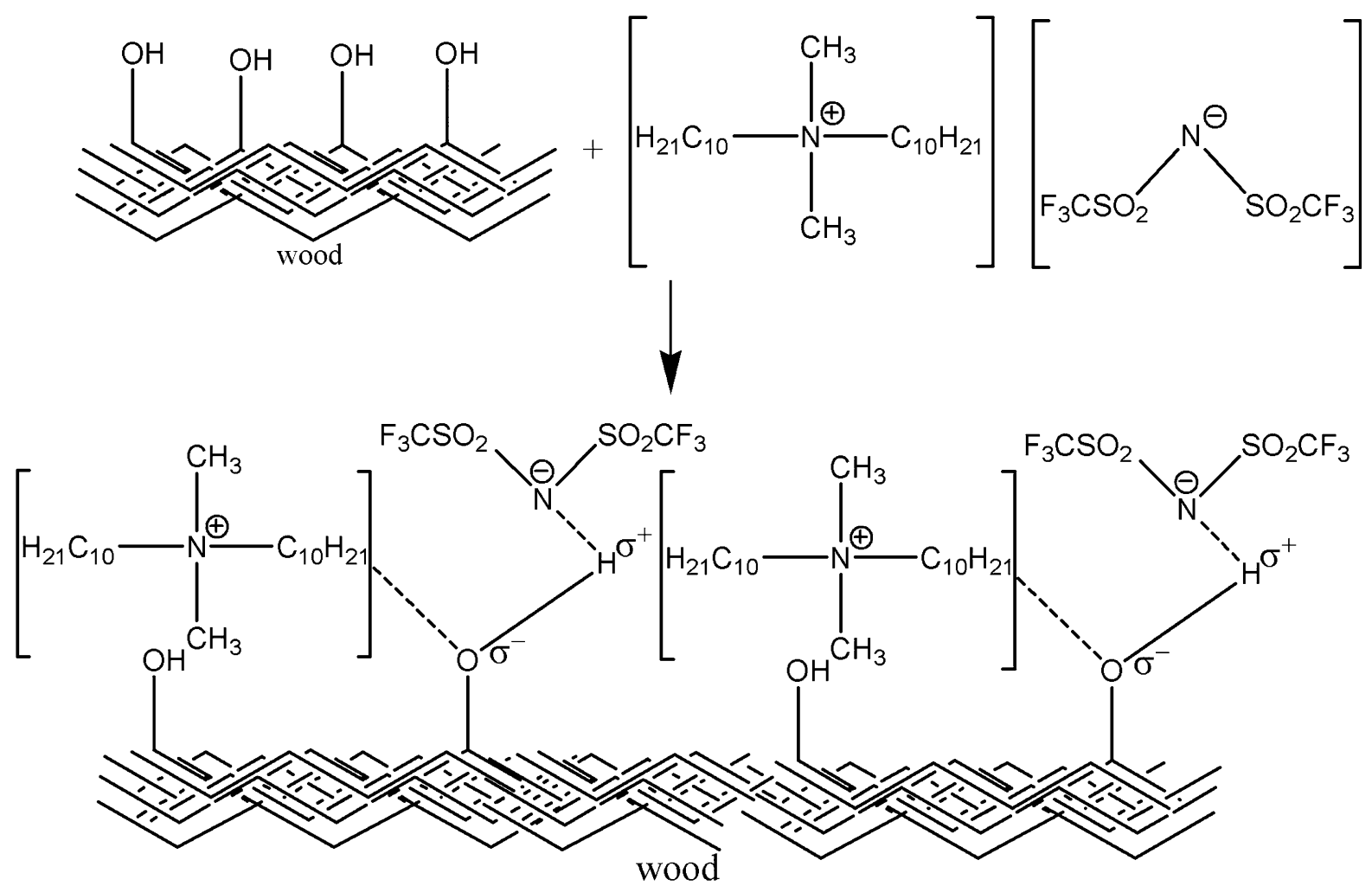

Fig. 4 Proposed mechanism of interaction between hydroxyl groups from wood and the didecyldimethylammonium bis(trifluoromethylsulfonyl)imide

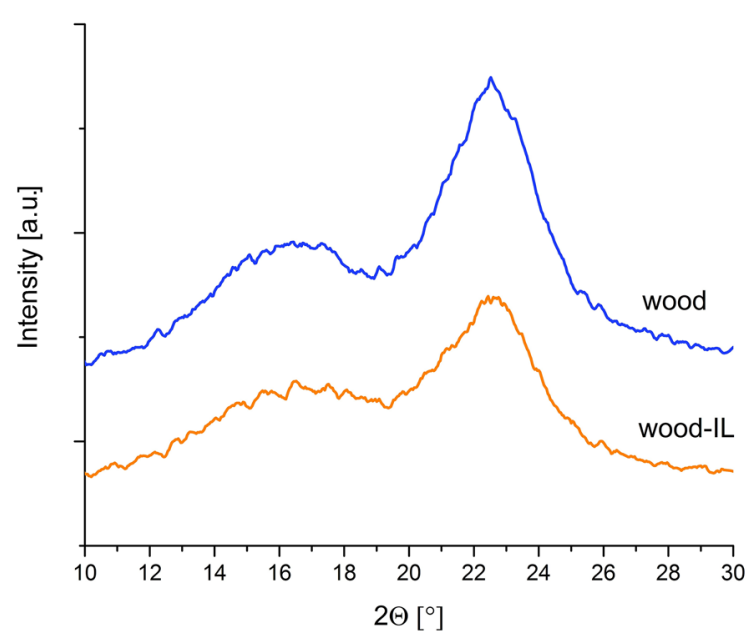

Fig. 5 X-ray diffraction pattern of pure wood and wood modified with ionic liquids

significant increase of $\mathrm{T}_{\mathrm{c}}$-only by $4{ }^{\circ} \mathrm{C}$. The obtained $\mathrm{T}_{\mathrm{c}}$ values indicate that pine wood treated with IL used as a filler for PP is characterized with lower nucleating abilities.

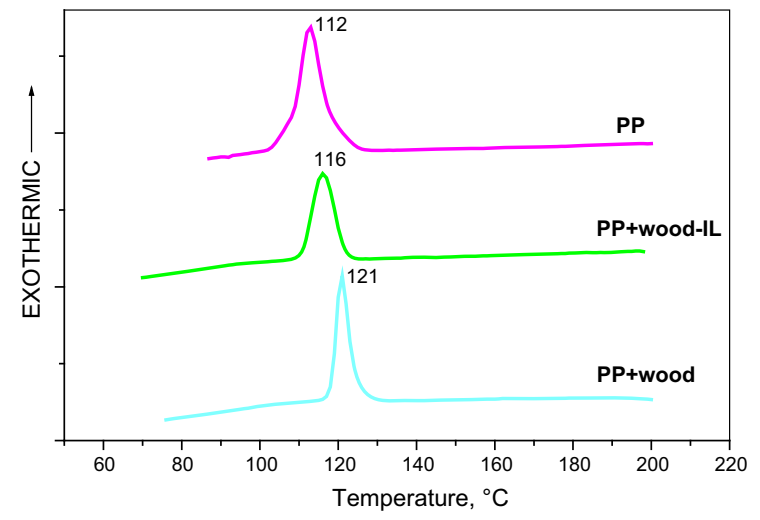

Fig. 6 DSC exotherms of PP and composite materials

In order to confirm the influence of ionic liquid modification on nucleating abilities of the wood filler the crystal conversion and crystallization half-times were defined. Figure 7 shows crystal conversion curves for composites and unfilled PP.

The shape of crystal conversion curves confirms the significance of chemical modification of the wood- 


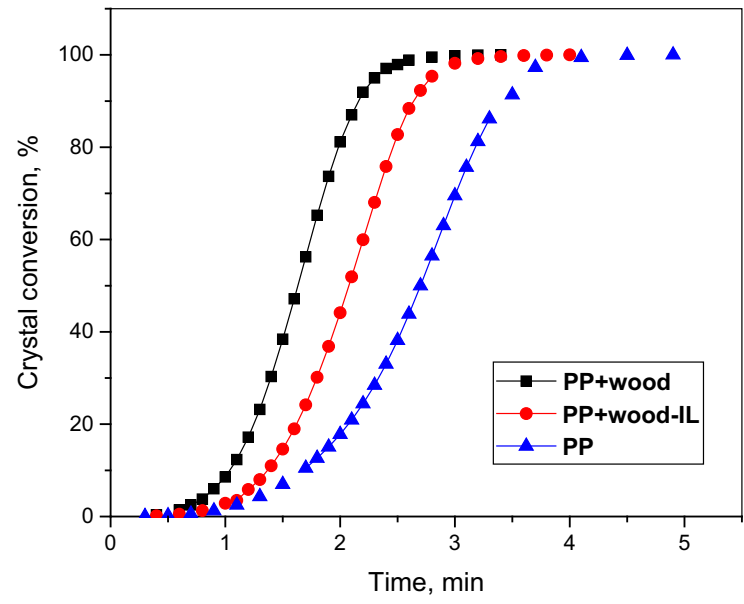

Fig. 7 The crystal conversion of PP matrix and composite materials

the highest crystal conversion rate was observed for composites with unmodified wood. Chemical treatment with IL was responsible for lowering the crystal conversion rate. However, values obtained for such composites were still higher than for PP matrix. Moreover, in comparison to unfilled PP, incorporation of each type of the wood filler caused a decrease of crystallization half-times (Table 1). Composites with modified wood were characterized with higher values of crystallization half-times $\left(\mathrm{t}_{0.5}=2.1 \mathrm{~min}\right)$ than composites with unmodified wood $\left(\mathrm{t}_{0.5}=1.6 \mathrm{~min}\right)$.

The determined kinetic parameters unambiguously show that chemical treatment of wood with didecyldimethylammonium bis(trifluoromethylsulfonyl)imide decreases the nucleating abilities of surface of the filler.

The obtained result are in line with other papers (Amash and Zugenmaier 2000; Arbelaiz et al. 2006; Borysiak 2007; Lee et al. 2010; Lenes and Gregersen 2006) in which decrease of nucleating abilities of the modified lignocellulosic fillers was noticed. These changes were discussed in terms of numerous factors

Table 1 The half-time of crystallization of PP and the composite materials

\begin{tabular}{ll}
\hline Sample & Half-time of crystallization $(\min )(\mathrm{SD})$ \\
\hline $\mathrm{PP}$ & $2.7( \pm 0.18)$ \\
$\mathrm{PP}+$ wood & $1.6( \pm 0.11)$ \\
$\mathrm{PP}+$ wood-IL & $2.1( \pm 0.14)$ \\
\hline
\end{tabular}

such as topography of the surface, polymorphism, chemical composition, and thermal conductivity. It is worth emphasizing that there is no unambiguous data regarding the characteristics of surfaces that are active in heterogeneous nucleation process. However the mechanism of this process is still not fully understood.

In Fig. 8 the crystallization process of $\mathrm{PP}$ in presence of two types of filler, at $136{ }^{\circ} \mathrm{C}$, is presented.

In Fig. 8a formation of transcrystalline structures of polymer matrix in presence of untreated wood filler can be observed. Such phenomena, called transcrystallization, is related to the surface of the filler that has a lot of active sites which are potentially responsible for high density nucleation. As a consequence, crystallites in polymer matrix tend to grow in a direction
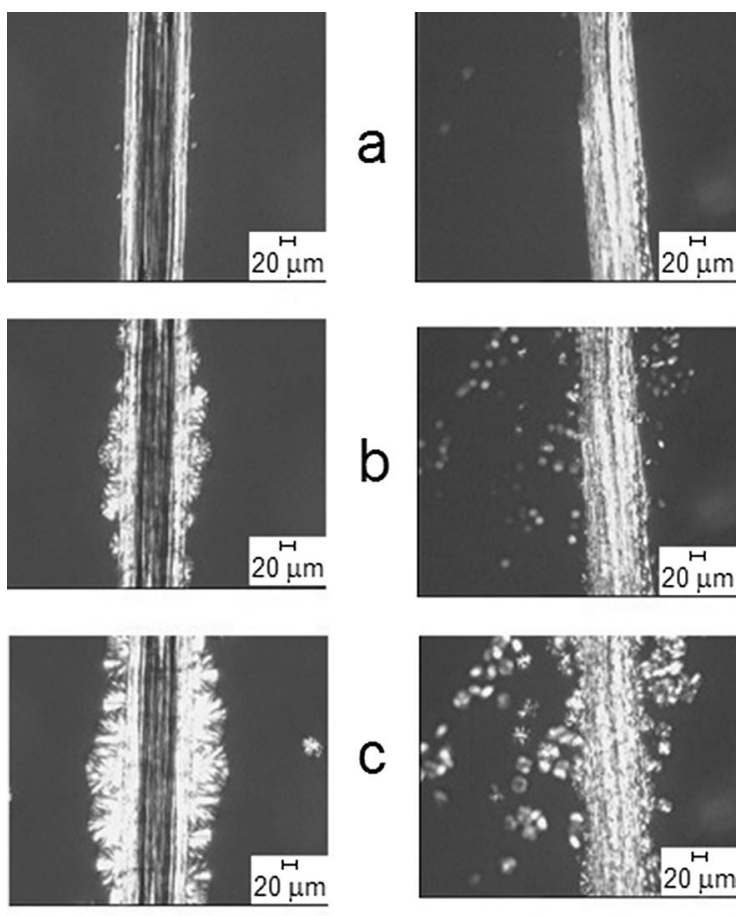

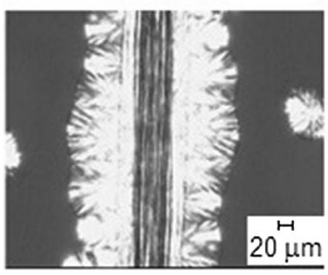

A

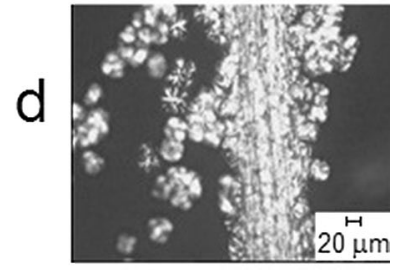

B
Fig. 8 Optical micrographs of PP morphologies obtained in the presence of: A crude wood, $\mathbf{B}$ wood modified with ionic liquid after (a $1 \mathrm{~min}, \mathbf{b} 2 \mathrm{~min}, \mathbf{c} 4 \mathrm{~min}, \mathbf{d} 6 \mathrm{~min}$ ) 
perpendicular to the surface of the filler. The transcrystallization can take place only if energetic conditions of the nucleation process are more favorable on the surface of the filler than in bulk of the polymer (Karger-Kocsis 1994).

The crystallization process is completely different in presence of ionic liquid treated wood (Fig. 8b). In this case, formation of large amounts of small spherulites in polymer was observed. The transcrystalline layer was formed, too, but its density was very low. That means that the chemical modification of the filler decreased the nucleating activity of its surface. Moreover, the crystal growth rate of transcrystalline layer for composite with untreated wood was $14.4 \mu \mathrm{m} /$ min. Composite systems containing wood after modification with ionic liquid were characterized by lower growth rates (ca. $4.2 \mu \mathrm{m} / \mathrm{min}$ ).

Even though transcrystalline structures are an important factor that needs consideration during formation of composites, mechanism of their formation is still not fully understood. Furthermore, relations between the chemical treatment of lignocellulosic fillers and formation of transcrystalline structures are very divergent. Nonetheless, literature studies have shown that different types of chemical treatment have a distinct influence on the nucleating abilities of surface of the filler. An analysis of published papers shows that chemical modification can either decrease nucleating abilities of lignocellulosic filler (Amash and Zugenmaier 2000; Arbelaiz et al. 2006; Borysiak 2013a, b; Gray 1974; Lee et al. 2010; Lenes and Gregersen 2006; Quillin et al. 1993) or on the contrary, enhance its nucleating abilities (Joseph et al. 2003; Zafeiropoulos et al. 2001). Based on literature data, it is known that transcrystallization results from molecular interactions between PP and cellulose (Felix and Gatenholm 1994). Proper configuration provides interactions between methyl groups of PP and glycosidic bonds present on surface of the cellulose. Electron density around methyl group is high enough to enable formation of van der Waals interactions with atom of oxygen present in glycosidic bond. Distance between two methyl groups (along c axis) is $0.65 \mathrm{~nm}$ and is comparable to the distance between oxygen atoms in glycosidic bond $(0.66 \mathrm{~nm})$. This compatibility of dimensions may be a reason for transcrystalline structures formation abilities. Also Quillin (Quillin et al. 1993) stated that there is a strong dimensional adjustment between cellulose chains
$(0.82 \mathrm{~nm})$ and methyl groups of PP $(0.84 \mathrm{~nm})$. Such molecular compatibility is believed to determine the epitaxial growth of transcrystalline layers on the surface of cellulose. It is likely that the chemical modification of wood, caused some changes in molecular sizes of cellulose, and thus had a negative influence on crystallographic adjustment of cellulose and PP. The conducted WAXS studies have shown that a decrease of crystallinity degree of wood modified with IL is a result of restrictions in interand intramolecular hydrogen bonds within the cellulose crystalline region. Consequently, a crystallographic adjustment between cellulose chains and macromolecules of PP becomes impaired. Moreover, another aspect that needs to be taken into consideration is surface and topography of the wood particles. Based on literature (Borysiak 2009) it is known that chemical modification of lignocellulosic fillers causes smoothing of their surface and, in result, lowering their nucleating activity. Greater roughness of the native wood surfaces causes thermal stress concentration and enhances the nucleating process. On the other hand, modification of wood with ionic liquid causes smoothing of wood surface, and in consequence the thermal stress that is responsible for transcrystallization is sufficiently small.

Effect of chemical modification of wood on the supermolecular structure of composite materials

The aim of WAXS studies was to analyze the influence of chemical modification of wood on formation of supermolecular structure of composites obtained in typical processing conditions. An important factor determining formation of hexagonal form of PP during extrusion and injection molding processes are shearing forces (Garbarczyk et al. 2002; Leugering and Kirsch 1973; Varga and Karger-Kocsis 1996).

The X-ray diffraction patterns show the crystallisation of PP in the presence of unmodified and modified with IL wood (Fig. 9).

In the diffraction curves a peak coming from $\beta$ phase of PP (at $2 \Theta=16.2^{\circ}$ ) and peaks coming from monoclinic $\alpha$-PP can be distinguished. There was a great divergence in intensity of peak coming from hexagonal form of PP. Unfilled PP was characterized with the lowest, $5 \%$, content of $\beta$-phase. Introduction into polymer matrix with $40 \%$ of untreated wood led to 


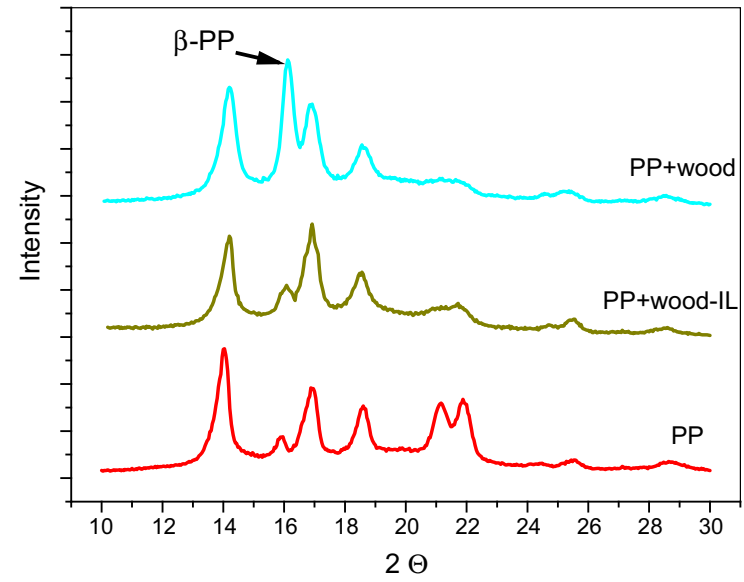

Fig. 9 X-ray diffraction patterns of PP matrix and composites with various fillers

formation of high amounts, ca. 36\%, of hexagonal form of PP. The value calculated for composite filled with modified wood turned out to be surprising, since there was only $8 \%$ of $\beta$-PP, which is comparable to the result obtained for unfilled polymer matrix.

This interesting result should be discussed in terms of two aspects. Firstly, it can be seen that composites with the ionic liquid modified wood are characterized with lower amount of $\beta$-PP. It can be presumed that decreased roughness of the modified wood filler resulted in presence of lower shear forces which are known to be responsible for $\beta$-PP formation. Similar results were reported by Xie (2002), who studied PP composites filled with sisal fibers. An enhanced adhesion, resulting from addition of SEBS compatibilizer, was found to decrease the content of hexagonal form of PP. Authors state that the chemical treatment changed the topography of surface of cellulosic fillers. This idea is also confirmed by other authors, who tested PP composites with flax (Zafeiropoulos et al. 2002) and Kevlar fibers (Wang and Liu 1999). Also in our previous research (Borysiak 2009) chemical modification of wood with acid anhydrides was found to be responsible for decrease of content of $\beta$-form of PP. Moreover, SEM studies have shown that applied modification introduced significant changes in topography of wood. Untreated wood was characterized with the highest roughness of the surface, whereas chemically treated sample was definitely smoother.

The second possible explanation of the variation in the amount of the hexagonal form versus kind of fillers may be related to the kinetic aspect of formation of both polymorphic structures of isotactic PP. In comparison with the composites containing the untreated wood, the chemical modification of wood with IL decreased its abilities to form $\beta$ phase of PP. Transformation from $\beta$-PP to more stable form of $\alpha$-PP is known to be a characteristic feature of the polymorphism of PP (Lezak et al. 2006; Lotz 1998; Varga 1986). The observed differences in amount of each polymorphic form of PP are a result of chemical modification of the wood filler and can be interpreted in terms of changes in nucleating abilities of the surface of the wood, which was already discussed in part 3.2.

It can be stated that deterioration of the nucleating abilities of the lignocellulosic filler after chemical modification facilitates the $\beta \rightarrow \alpha$ phase conversion. It was noted that for composites containing filler with low nucleating abilities (ionic liquid treated wood), not only the speed of formation of the transcrystalline structures, but also crystal conversion rate was slower. In such composites also crystallization half-times were longer. That may promote relaxation processes and $\beta \rightarrow \alpha$ phase conversion.

Effect of treatment on the mechanical properties

It is believed that chemical treatment of the filler enhances the mechanical properties of composites containing such modified filler. Our findings are in line with this hypothesis. Table 2 presents tensile strength $(\mathrm{Rg})$, Young's modulus (E), elongation at break (c), and impact strength parameters obtained for tested specimens.

The results show that the use of both, modified and unmodified filler influences the mechanical properties of PP composites. However, composites with ionic liquid treated wood were characterized with higher values of all tested parameters than composites with untreated wood.

In comparison with matrix, addition of untreated and treated wood caused the tensile strength to increase to 34.5 and $38.6 \mathrm{MPa}$, respectively. The possible explanation of this behavior may be enhanced stress transfer between the wood and the polymer matrix. It should be noted that the modification of wood was responsible for changes in values of tensile strength parameter. That is a result of improved interfacial adhesion between polymer matrix and wood fillers. 
Table 2 Tensile mechanical properties and impact strength of PP and composite materials

\begin{tabular}{lllcl}
\hline Sample & Rg $(\mathrm{MPa})$ & $\mathrm{E}(\mathrm{GPa})$ & $\varepsilon(\%)$ & Impact strength $\left(\mathrm{kJ} / \mathrm{m}^{2}\right)$ \\
\hline PP & $30.40 \pm 0.08$ & $1.58 \pm 0.11$ & $487.00 \pm 22.10$ & $56.40 \pm 0.77$ \\
PP + wood & $34.50 \pm 0.41$ & $2.41 \pm 0.22$ & $3.10 \pm 0.72$ & $25.90 \pm 1.65$ \\
PP + wood-IL & $38.60 \pm 0.19$ & $2.63 \pm 0.13$ & $9.40 \pm 0.11$ & $29.70 \pm 1.89$ \\
\hline
\end{tabular}

Similar relationship was observed for Young's modulus, however the highest value of Young's modulus, $2.63 \mathrm{GPa}$, was noted for composite containing modified wood. The explanation is similar to that of the tensile strength. The tensile modulus increased with the use of modified fillers, which is believed to be due to better interfacial bonding between the modified filler and matrix.

As expected, the incorporation of wood fillers in polymer matrix was responsible for a major decrease of ductility. Elongation at break for PP reached value of $487 \%$, whereas for composite with untreated wood the value of this parameter dropped to ca. 3\%. For composites with ionic liquid treated wood the elongation at break was found to be $9.4 \%$. Stronger interphase interactions resulting from modification of wood with ionic liquid are responsible for increase of elongation at break in such composites. As opposed to materials with unmodified wood that were characterized with brittleness, materials with ionic liquid treated wood had definitely wider range of elastic deformations.

Values of all mechanical parameters obtained for PP are consistent with literature (Borysiak 2013a). Composites containing wood were characterized with slightly higher values of tensile strength and elastic modulus than matrix. This strengthening effect observed for samples with ionic liquid treated wood may be attributed to better adhesion between components of the composite (Croitoru et al. 2018). The increased adhesion, enabling more efficient stress transfer in composite system, is most likely a result of increased wettability of the wood fibers. This hypothesis is also supported by the research of Mahmood et al. (Mahmood et al. 2015), who investigated composites fabricated from lignocellulosic biomass pretreated with ionic liquids.

The impact strength of unfilled polymer matrix reached the value of $56.4 \mathrm{~kJ} / \mathrm{m}^{2}$. Results show that addition of wood flour, both untreated and treated, caused the impact strength to decrease to 25.9 and $29.7 \mathrm{~kJ} / \mathrm{m}^{2}$.

The decrease of impact strength noted for composites with wood can be associated with introduction into polymer matrix weak interfacial regions in which stress concentration occurs (Nygård et al. 2008). Presence of the filler is also known to be responsible for enhanced formation of holes and voids leading to lower impact strength values (Adhikary et al. 2008). The fact that ionic liquid treatment reduces the roughness of wood was described by Croitoru et al. (2011). Therefore, it can be stated that chemical modification of wood not only enhanced the adhesion between matrix and filler, but also limited the amount of voids present in composites, and thus had an effect on its mechanical properties.

It ought to be stressed that even though composites with unmodified wood contained higher amount of $\beta$ PP form its impact strength was not increased. This may be due to the fact that not only polymorphism but also phenomena taking place at the polymer-filler interface, which is controlled by chemical modifications of lignocellulosic filler, should be taken into consideration. Chemical modification of wood was found to enhance adhesion and formation of small spherulitic structures and thus increase impact strength of this composite.

\section{Conclusions}

Application of newly synthesized ionic liquid-didecyldimethylammonium bis(trifluoromethylsulfonyl)imide - was proved to be an effective method for pine wood modification, resulting in preparation of polypropylene/wood composites with good mechanical properties. It should be emphasized that for the first time ionic liquid was applied for hydrophobization of surface of lignocellulosic filler. So far ionic liquids 
were used only as solvents for already known chemical modifiers.

The results of FTIR and XRD analyses indicate reactivity of ionic liquid with wood. The characteristic bands of the sulphur-oxygen, nitrogen-oxygen, and nitrogen-carbon bonds originating from ionic liquid molecule were observed in the spectra of treated wood. Ionic liquid chemical modification of wood resulted in lowering of nucleating abilities what was manifested by lower crystallization temperatures, decrease of crystal conversion rate, and higher crystallization half-times of polymer matrix. Moreover, a reduction in tendency to form transcrystalline layer was observed. Instead of transcrystalline layer a phase of small spherulites with high density was formed.

In comparison with composites containing untreated wood, composites with modified wood filler were characterized with completely different supermolecular structure. Materials filled with untreated wood contained a high amount of $\beta$-phase of polypropylene, whereas introduction into polymer matrix the ionic liquid treated wood decreased the amount of this hexagonal phase to level comparable to unfilled polypropylene. This interesting fact can be interpreted in terms of changes in nucleating abilities of wood, controlled by its chemical modification and $\beta \rightarrow \alpha$ polymorphic transformation as well.

In view of obtaining proper, assumed properties of composite materials understanding the relationship between the nucleation ability of lignocellulosic filler and the content of polypropylene polymorphs is crucial. It should be stressed, that due to the fact that each polymorphic form is characterized by different properties their presence in the polymer matrix influences the physicochemical properties of the produced materials.

Based on the results obtained in this paper it follows that the mechanical properties of wood composites are a resultant of two factors: the polymorphic structure of polymer matrix and nucleation ability controlled by chemical modifications of lignocellulosic components.

Acknowledgments This research was supported by the grant of Poznan University of Technology No. 03/32/DSPB/0803.

Open Access This article is distributed under the terms of the Creative Commons Attribution 4.0 International License (http:// creativecommons.org/licenses/by/4.0/), which permits unrestricted use, distribution, and reproduction in any medium, provided you give appropriate credit to the original author(s) and the source, provide a link to the Creative Commons license, and indicate if changes were made.

\section{References}

Adhikary KB, Pang S, Staiger MP (2008) Dimensional stability and mechanical behaviour of wood-plastic composites based on recycled and virgin high-density polyethylene (HDPE). Compos B Eng 39:807-815. https://doi.org/10. 1016/j.compositesb.2007.10.005

Amash A, Zugenmaier P (2000) Morphology and properties of isotropic and oriented samples of cellulose fibrepolypropylene composites. Polymer 41:1589-1596. https://doi.org/10.1016/S0032-3861(99)00273-6

Arbelaiz A, Fernández B, Ramos JA, Mondragon I (2006) Thermal and crystallization studies of short flax fibre reinforced polypropylene matrix composites: effect of treatments. Thermochim Acta 440:111-121. https://doi. org/10.1016/j.tca.2005.10.016

Bagheri M, Rodríguez H, Swatloski RP, Spear SK, Daly DT, Rogers RD (2008) Ionic liquid-based preparation of cellulose-dendrimer films as solid supports for enzyme immobilization. Biomacromol 9:381-387. https://doi.org/ $10.1021 / \mathrm{bm} 701023 \mathrm{w}$

Borysiak S (2007) Determination of nucleating ability of wood for non-isothermal crystallisation of polypropylene. J Therm Anal Calorim 88:455-462. https://doi.org/10. 1007/s10973-006-8077-1

Borysiak S (2009) Supermolecular structure of wood/ polypropylene composites: I. The influence of processing parameters and chemical treatment of the filler. Polym Bull 64:275. https://doi.org/10.1007/s00289-009-0202-4

Borysiak S (2013a) Fundamental studies on lignocellulose/ polypropylene composites: effects of wood treatment on the transcrystalline morphology and mechanical properties. J Appl Polym Sci 127:1309-1322. https://doi.org/10. 1002/app.37651

Borysiak S (2013b) Influence of cellulose polymorphs on the polypropylene crystallization. J Therm Anal Calorim 113:281-289. https://doi.org/10.1007/s10973-013-3109-0

Brandt A, Grasvik J, Hallett JP, Welton T (2013) Deconstruction of lignocellulosic biomass with ionic liquids. Green Chem 15:550-583. https://doi.org/10.1039/C2GC36364J

Burley J, Evans J, Youngquist JA (2004) Encyclopedia of forest sciences. Elsevier Science, Oxford

Croitoru C, Patachia S, Cretu N, Boer A, Friedrich C (2011) Influence of ionic liquids on the surface properties of poplar veneers. Appl Surf Sci 257:6220-6225. https://doi. org/10.1016/j.apsusc.2011.02.041

Croitoru C, Varodi AM, Timar MC, Roata IC, Stanciu EM, Pascu A (2018) Wood-plastic composites based on HDPE and ionic liquid additives. J Mater Sci 53:4132-4143. https://doi.org/10.1007/s10853-017-1826-7

Dominkovics Z, Dányádi L, Pukánszky B (2007) Surface modification of wood flour and its effect on the properties of PP/wood composites. Compos A Appl Sci Manuf 
38:1893-1901. https://doi.org/10.1016/j.compositesa. 2007.04.001

Edgar KJ, Buchanan CM, Debenham JS, Rundquist PA, Seiler BD, Shelton MC, Tindall D (2001) Advances in cellulose ester performance and application. Prog Polym Sci 26:1605-1688. https://doi.org/10.1016/S00796700(01)00027-2

Faruk O, Bledzki AK, Fink H-P, Sain M (2012) Biocomposites reinforced with natural fibers: 2000-2010. Prog Polym Sci 37:1552-1596. https://doi.org/10.1016/j.progpolymsci. 2012.04.003

Feifel S, Stübs O, Seibert K, Hartl J (2015) Comparing woodpolymer composites with solid wood: the case of sustainability of terrace flooring. Eur J Wood Wood Prod 73:829-836. https://doi.org/10.1007/s00107-015-0953-6

Felix JM, Gatenholm P (1994) Effect of transcrystalline morphology on interfacial adhesion in cellulose/polypropylene composites. J Mater Sci 29:3043-3049. https://doi.org/10. 1007/bf01117618

Garbarczyk J, Paukszta D, Borysiak S (2002) Polymorphism of isotactic polypropylene in presence of additives, in blends and in composites. J Macromol Sci Part B 41:1267-1278. https://doi.org/10.1081/MB-120013096

Gray DG (1974) Polypropylene transcrystallization at the surface of cellulose fibers. J Polym Sci Polym Lett Ed 12:509-515. https://doi.org/10.1002/pol.1974.130120903

Harper DP, Laborie M-PG, Wolcott MP (2009) The impact of polypropylene-graft-maleic anhydride on the crystallization and dynamic mechanical properties of isotactic polypropylene. J Appl Polym Sci 111:753-758. https://doi. org/10.1002/app.29100

Hill CAS (2007) Wood modification: chemical, thermal and other processes. Wiley, Hoboken

Hindeleh AM, Johnson DJ (1971) The resolution of multipeak data in fibre science. J Phys D Appl Phys 4:259

Jones AT, Aizlewood JM, Beckett DR (1964) Crystalline forms of isotactic polypropylene. Die Makromol Chem 75:134-158. https://doi.org/10.1002/macp.1964. 020750113

Joseph PV, Joseph K, Thomas S (1999) Effect of processing variables on the mechanical properties of sisal-fiber-reinforced polypropylene composites. Compos Sci Technol 59:1625-1640. https://doi.org/10.1016/S02663538(99)00024-X

Joseph PV, Joseph K, Thomas S, Pillai CKS, Prasad VS, Groeninckx G, Sarkissova M (2003) The thermal and crystallisation studies of short sisal fibre reinforced polypropylene composites. Compos A Appl Sci Manuf 34:253-266. https://doi.org/10.1016/S1359835X(02)00185-9

Kalia S, Kaith BS, Kaur I (2011) Cellulose fibers: bio- and nanopolymer composites: green chemistry and technology. Springer, Berlin

Karger-Kocsis J (1994) Polypropylene structure, blends and composites: structure and morphology, vol 1. Springer, Dordrecht

Keith HD, Padden FJ Jr, Walter NM, Wyckoff HW (1959) Evidence for a second crystal form of polypropylene. J Appl Phys 30:1485-1488. https://doi.org/10.1063/1. 1734986
Khoshkava V, Kamal MR (2014) Effect of drying conditions on cellulose nanocrystal (CNC) agglomerate porosity and dispersibility in polymer nanocomposites. Powder Technol 261:288-298. https://doi.org/10.1016/j.powtec.2014.04. 016

Klemm D, Heublein B, Fink H-P, Bohn A (2005) Cellulose: fascinating biopolymer and sustainable raw material. Angew Chem Int Ed 44:3358-3393. https://doi.org/10. 1002/anie. 200460587

Köhler S, Heinze T (2007) Efficient synthesis of cellulose furoates in 1- $N$-butyl-3-methylimidazolium chloride. Cellulose 14:489-495. https://doi.org/10.1007/s10570-0079138-8

Lee BG, Lee S, Via BK (2010) Influence of surface morphology of the kraft pulp fibers on the growth of the transcrystalline layer of polypropylene. J Appl Polym Sci 116:1958-1966. https://doi.org/10.1002/app.31289

Lee HV, Hamid SBA, Zain SK (2014) Conversion of lignocellulosic biomass to nanocellulose: structure and chemical process. Sci World J 2014:20. https://doi.org/10.1155/ 2014/631013

Lenes M, Gregersen ØW (2006) Effect of surface chemistry and topography of sulphite fibres on the transcrystallinity of polypropylene. Cellulose 13:345-355. https://doi.org/10. 1007/s10570-006-9057-0

Leugering VHJ, Kirsch G (1973) Beeinflussung der kristallstruktur von isotaktischem polypropylen durch kristallisation aus orientierten schmelzen. Die Angew Makromol Chem 33:17-23. https://doi.org/10.1002/apmc.1973. 050330102

Lezak E, Bartczak Z, Galeski A (2006) Plastic deformation behavior of $\beta$-phase isotactic polypropylene in plane-strain compression at room temperature. Polymer 47:8562-8574. https://doi.org/10.1016/j.polymer.2006.10.016

Liu CF, Sun RC, Zhang AP, Ren JL (2007) Preparation of sugarcane bagasse cellulosic phthalate using an ionic liquid as reaction medium. Carbohyd Polym 68:17-25. https:// doi.org/10.1016/j.carbpol.2006.07.002

Lotz B (1998) $\alpha$ and $\beta$ phases of isotactic polypropylene: a case of growth kinetics 'phase reentrency' in polymer crystallization. Polymer 39:4561-4567. https://doi.org/10.1016/ S0032-3861(97)10147-1

Mahmood H, Moniruzzaman M, Yusup S, Akil HM (2015) Comparison of some biocomposite board properties fabricated from lignocellulosic biomass before and after ionic liquid pretreatment. Chem Eng. https://doi.org/10.3303/ cet 1545119

Michalska-Pożoga I, Tomkowski R, Rydzkowski T, Thakur VK (2016) Towards the usage of image analysis technique to measure particles size and composition in wood-polymer composites. Ind Crops Prod 92:149-156. https://doi.org/ 10.1016/j.indcrop.2016.08.005

Ninomiya K et al (2017) Ionic liquid pretreatment of bagasse improves mechanical property of bagasse/polypropylene composites. Ind Crops Prod 109:158-162. https://doi.org/ 10.1016/j.indcrop.2017.08.019

Nygård P, Tanem BS, Karlsen T, Brachet P, Leinsvang B (2008) Extrusion-based wood fibre-PP composites: Wood powder and pelletized wood fibres-a comparative study. Compos Sci Technol 68:3418-3424. https://doi.org/10.1016/j. compscitech.2008.09.029 
Oksman K, Clemons C (1998) Mechanical properties and morphology of impact modified polypropylene-wood flour composites. J Appl Polym Sci 67:1503-1513. https://doi. org/10.1002/(SICI)1097-4628(19980228)67:9<1503: AID-APP1>3.0.CO;2-H

Quillin DT, Caulfield DF, Koutsky JA (1993) Crystallinity in the polypropylene/cellulose system. I. Nucleation and crystalline morphology. J Appl Polym Sci 50:1187-1194. https://doi.org/10.1002/app.1993.070500709

Rabiej S (1991) A comparison of two X-ray diffraction procedures for crystallinity determination. Eur Polym J 27:947-954. https://doi.org/10.1016/00143057(91)90038-P

Schenzel A, Hufendiek A, Barner-Kowollik C, Meier MAR (2014) Catalytic transesterification of cellulose in ionic liquids: sustainable access to cellulose esters. Green Chem 16:3266-3271. https://doi.org/10.1039/C4GC00312H

Son S-J, Lee Y-M, Im S-S (2000) Transcrystalline morphology and mechanical properties in polypropylene composites containing cellulose treated with sodium hydroxide and cellulase. J Mater Sci 35:5767-5778. https://doi.org/10. 1023/a:1004827128747

Thakur VK, Singha AS, Thakur MK (2013) Natural cellulosic polymers as potential reinforcement in composites: physicochemical and mechanical studies. Adv Polym Technol 32:E427-E435. https://doi.org/10.1002/adv. 21290

Thakur VK, Thakur MK, Gupta RK (2014a) Graft copolymers of natural fibers for green composites. Carbohyd Polym 104:87-93. https://doi.org/10.1016/j.carbpol.2014.01.016

Thakur VK, Vennerberg D, Kessler MR (2014b) Green aqueous surface modification of polypropylene for novel polymer nanocomposites. ACS Appl Mater Interfaces 6:9349-9356. https://doi.org/10.1021/am501726d

Varga J (1986) Melting memory effect of the $\beta$-modification of polypropylene. J Therm Anal 31:165-172. https://doi.org/ 10.1007/bf01913897

Varga J, Karger-Kocsis J (1996) Rules of supermolecular structure formation in sheared isotactic polypropylene melts. J Polym Sci, Part B Polym Phys 34:657-670. https:// doi.org/10.1002/(SICI)1099-0488(199603)34:4<657: AID-POLB6>3.0.CO;2-N

Wang C, Liu CR (1999) Transcrystallization of polypropylene composites: nucleating ability of fibres. Polymer 40:289-298. https://doi.org/10.1016/S00323861(98)00240-7

Wasserscheid P, Welton T (2008) Ionic liquids in synthesis. Wiley, Weinheim

Woźniak M, Grząbka-Zasadzińska A, Skrzypczak A, Ratajczak I, Sławomir B (2017) Applicability of didecyldimethylammonium bis(trifluoromethylsulfonyl) imide in pine wood (Pinus sylvestris L.) modification. Annals Warsaw University of Life Sciences, Forestry and Wood Technology, Warsaw, pp 44-47

Wu J, Zhang J, Zhang H, He J, Ren Q, Guo M (2004) Homogeneous acetylation of cellulose in a new ionic liquid. Biomacromolecules 5:266-268. https://doi.org/10.1021/ bm034398d

Xie XL, Fung KL, Li RKY, Tjong SC, Mai YW (2002) Structural and mechanical behavior of polypropylene/maleated styrene-(ethylene-co-butylene)-styrene/sisal fiber composites prepared by injection molding. J Polym Sci, Part B Polym Phys 40:1214-1222. https://doi.org/10.1002/polb. 10175

Xie H, King A, Kilpelainen I, Granstrom M, Argyropoulos DS (2007) Thorough chemical modification of wood-based lignocellulosic materials in ionic liquids. Biomacromolecules 8:3740-3748. https://doi.org/10.1021/ bm700679s

Xu S, Zhang J, He A, Li J, Zhang H, Han CC (2008) Electrospinning of native cellulose from nonvolatile solvent system. Polymer 49:2911-2917. https://doi.org/10.1016/j. polymer.2008.04.046

Zafeiropoulos NE, Baillie CA, Matthews FL (2001) A study of transcrystallinity and its effect on the interface in flax fibre reinforced composite materials. Compos A Appl Sci Manuf 32:525-543. https://doi.org/10.1016/S1359$835 \mathrm{X}(00) 00058-0$

Zafeiropoulos NE, Williams DR, Baillie CA, Matthews FL (2002) Engineering and characterisation of the interface in flax fibre/polypropylene composite materials. Part I. Development and investigation of surface treatments. Compos Part A Appl Sci Manuf 33:1083-1093. https://doi. org/10.1016/S1359-835X(02)00082-9

Zhang J et al (2009a) Structural changes of microcrystalline cellulose during interaction with ionic liquids. J Biobased Mater Bioenergy 3:69-74. https://doi.org/10.1166/jbmb. 2009.1009

Zhang J, Park CB, Rizvi GM, Huang H, Guo Q (2009b) Investigation on the uniformity of high-density polyethylene/wood fiber composites in a twin-screw extruder. J Appl Polym Sci 113:2081-2089. https://doi.org/10.1002/ app.29991

Zhang J, Wu J, Cao Y, Sang S, Zhang J, He J (2009c) Synthesis of cellulose benzoates under homogeneous conditions in an ionic liquid. Cellulose 16:299-308. https://doi.org/10. 1007/s10570-008-9260-2

Zhu S et al (2006) Dissolution of cellulose with ionic liquids and its application: a mini-review. Green Chem 8:325-327. https://doi.org/10.1039/B601395C 